\title{
Erratum to: Case Report
}

\section{Unicameral Bone Cysts in a Young Patient with Acquired Generalized Lipodystrophy}

James M. Gregory MD, Alexandre Arkader MD, Aqiba Bokhari MD, John P. Dormans MD

Published online: 4 May 2010

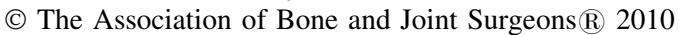

\section{Erratum to: Clin Orthop Relat Res \\ DOI 10.1007/s11999-009-1168-0}

The correct spelling of the third author's name is Aqiba Bokhari rather than Aqiba Bothari.

The online version of the original article can be found under doi:10.1007/s11999-009-1168-0.

J. M. Gregory

Department of Orthopaedic Surgery, Rush University, Chicago,

IL, USA

\section{A. Arkader}

Children's Orthopaedic Center, Children's Hospital Los

Angeles, Keck School of Medicine, University of Southern

California, Los Angeles, CA, USA

\author{
A. Bokhari \\ Department of Pathology, The Children's Hospital of \\ Philadelphia, Philadelphia, PA, USA
}

J. P. Dormans $(\square)$

Department of Orthopaedic Surgery, The Children's Hospital of Philadelphia, University of Pennsylvania School of Medicine,

2nd Floor Wood Center, 34th Street and Civic Center Boulevard, Philadelphia, PA 19104-4399, USA

e-mail: dormans@email.chop.edu 